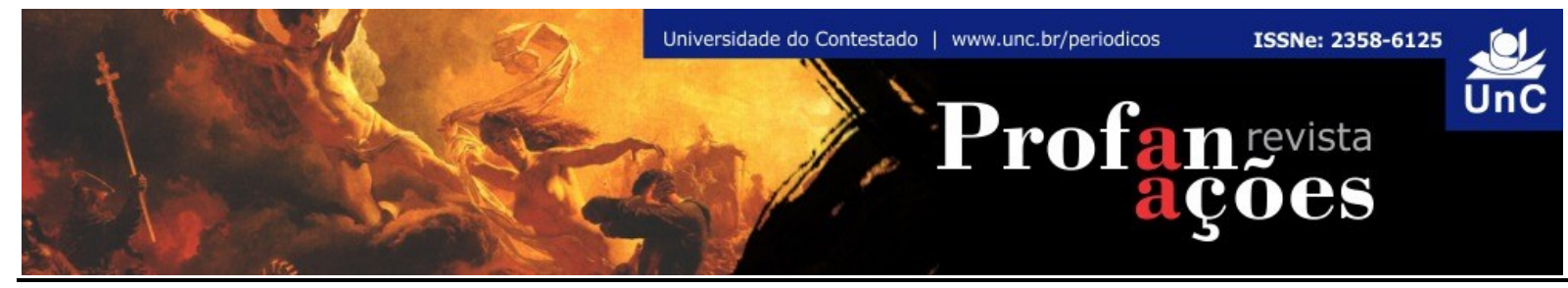

\title{
OS DIÁLOGOS DE BENJAMIN E AGAMBEN SOBRE PODER E VIOLÊNCIA: DESDOBRAMENTOS POSSÍVEIS PARA AS RELAÇÕES INTERNACIONAIS
}

\author{
Danillo Avellar Bragança ${ }^{1}$
}

\begin{abstract}
RESUMO: O presente texto tem como objetivo abordar o diálogo entre dois pensadores da teoria política pouco recepcionados no campo das Relações Internacionais, mas fundamentais para se entender a emergência de governos de natureza autoritária no mundo atual: Walter Benjamin e Giorgio Agamben. A influência do autor alemão sobre as pesquisas do pensador italiano são inegáveis, e o texto aborda conceitualmente as relações entre temas como o da violência pura, poder, biopoder e estado de exceção para abordar os problemas de natureza política e do exercício do poder dos Estados, utilizando-se do diálogo entre os dois para estender esta compreensão para o campo dos fenômenos internacionais, tão carentes de renovação conceitual e novas referências.
\end{abstract}

Palavras-chave: Poder. Estado de exceção. Violência. Teoria política. Relações Internacionais.

\section{THE DIALOGUES BETWEEN BENJAMIN AND AGAMBEN ABOUT POWER AND VIOLENCE: POSSIBLE DEVELOPMENTS FOR INTERNATIONAL RELATIONS}

\begin{abstract}
This text aims to address the dialogue between two thinkers of the political theory that are not quite accepted in the field of International Relations, but both fundamental to understand the emergence of authoritarian governments in the current world: Walter Benjamin and Giorgio Agamben. The German author's influence on the Italian thinker's research is undeniable, and the text conceptually addresses the relationships between themes such as pure violence, power, biopower and the state of exception to tackle problems of political nature and the exercise of the states power, using this dialogue to extend theirs comprehension to the field of international phenomena, so lacking in conceptual renewal and new references.
\end{abstract}

Keywords: Power. State of exception. Violence. Political theory. International Relations

\footnotetext{
1 Doutorando em Ciência Política pela Universidade Federal Fluminense; Mestre em Relações Internacionais pela Universidade do Estado do Rio de Janeiro; Professor-colaborador do Instituto de Relações Internacionais e Estudos Estratégicos da Universidade Federal Fluminense. Rio de Janeiro. Brasil. E-mail: dbraganca@id.uff.br
} 


\section{INTRODUÇÃO}

O mundo de hoje apresenta desafios cada vez mais intransponíveis para os saberes constituídos tradicionalmente pela Ciência Política e Relações Internacionais. Aquilo que dentro desta área chamamos de paradigma realista, que representam exatamente essa tradição do saber constituída após anos e anos, não conseguem mais diante deste quadro complexo apresentar soluções razoáveis para os operadores de política internacional e para os analistas. Temas cada vez mais prementes dentro do cenário internacional como a vigilância, segurança o controle e a governabilidade emergem como parte indissociável deste objeto de estudo que é o internacional. Esses elementos são definitivamente parte de um mundo que se renova a todo instante, mas que não tem essa renovação acompanhada pelo conhecimento instituído nas academias de saber, das grandes universidades, nas grandes escolas teóricas - como naturalmente deveria ser, já que os ritmos são inteiramente diferentes.

O autoritarismo está em fase de crescimento e mesmo que o contexto histórico não seja o mesmo na Guerra Fria existem focos internacionais de expansão desse autoritarismo ou neofascismo do século 21. A emergência de governos totalitários é uma realidade no cenário internacional e os casos são muitos. No entanto, mesmo que algumas características se repitam entre os governos totalitários do século 20 e o populismo de direita e de esquerda que emerge nesta fase do século 21 , o desafio de compreender e de evitar que cheguem ao exercício máximo dos seus dispositivos de poder não cabe, como se coloca desde a década de 1990, nos paradigmas anteriores de compreensão do mundo, pelo menos nos campos da Ciência Política e Relações Internacionais. É preciso, portanto explorar novas searas, trazendo para o difícil campo do Internacional outros instrumentos de compreensão já consolidados em outras áreas.

É preciso apontar que o campo das Ciências Políticas e Relações Internacionais - sobretudo o último - incorporam de forma muito lenta avanços na pesquisa que vem da filosofia política, da teoria do direito e do estudo das teorias de poder. Giorgio Agamben é ainda um tema bastante pouco explorado dentro das Relações Internacionais. Se a literatura que o autor produziu já é longa o suficiente para demonstrar a profundidade qualitativa do seu edifício teórico, é preciso fazê-lo 
também comunicar-se com outras áreas do conhecimento ainda alheias ao impacto que os estudos de Agamben vem produzindo. Nesse sentido, este texto tem objetivo geral de, a partir da interlocução entre Walter Benjamin e Giorgio Agamben acerca das teorias sobre a violência e seus desdobramentos como mecanismos de poder, apresentar hipóteses para que estas conexões sejam aproveitadas também no campo da Ciência Política e das Relações Internacionais. É fundamental que dentro deste esforço de incorporação criativa de novas formas de pensamento dentro das Relações Internacionais nomes como o de Walter Benjamin e Giorgio Agamben sejam de fato tratados como deveriam, para darem a sua contribuição no entendimento da complexa estrutura internacional que temos hoje. Não somente uma análise de conjuntura como se as contribuições de Agamben fossem pontuais e específicas. Mas dado que a extensão da sua pesquisa e produção de conhecimento é reconhecidamente tão profunda que de fato as conclusões de Agamben nesse momento podem servir de forma muito mais extensa e muito mais decisiva.

Esse texto então se desdobra da seguinte forma. Inicialmente apresentaremos a nossa leitura e contribuição sobre o debate entre Benjamin e Giorgio Agamben. É preciso repensar esse debate não de forma a invalidar o que foi dito antes, sobretudo no livro "Estado de Exceção". A ideia é atuar criativamente sobre esse debate entendendo como a incorporação da violência pura no interior dos ordenamentos jurídicos dos estados e posteriormente do sistema internacional contribuem para a existência de níveis internacionais onde os Estados podem agir de forma soberana de acordo com mecanismos previstos e de expedientes extrajurídicos. Importante ressaltar que esse texto é parte do desenvolvimento de minha tese de doutorado em Ciência Política na Universidade Federal Fluminense. Meu tema específico é o do narcotráfico na América do Sul e usa Agamben como principal marco teórico. Nesse sentido esse texto é parte do debate que pretendo realizar e que servirá de esteio para futuras pesquisas.

\section{ARGUMENTO GERAL}

A relação entre Benjamin (2016) e Agamben (2004) fica mais evidente no "Estado de Exceção", livro do autor italiano mais relevante para esta pesquisa. Grosso modo, o livro parte da proposta de explorar a zona que se constitui entre a 
ordem jurídica criada pelo Estado e pelo domínio da lei e a vida dos homens e mulheres que vivem, dos seres viventes. Esse é um espaço vazio que já é mencionado por Benjamin em outros momentos e que na verdade se torna um dos elementos-chaves da compreensão da filosofia do direito e da teoria política no século 20, sobretudo depois da emergência de experiências totalitárias do nazismo e do fascismo. Aliás, com muito êxito, o totalitarismo empreende a supressão total dessa diferenciação entre aquilo que é vida e, portanto exclusivas dos viventes e aquilo que é do direito e, portanto exclusivo do Estado, exatamente pela instauração daquilo que pelos termos de Agamben fica conhecido como estado de exceção. A ordem jurídica da normalidade, ou seja, aquela vigente em tempos de paz é suspensa de forma permanente e dá lugar a uma forma extralegal de direito que se justifica pela instabilidade e pela necessidade. (AGAMBEN, 2004).

Quando essa ordem jurídica normal sofre um nível de ameaça que o próprio estado julga bastante acentuada é possível deflagrar mecanismos presentes no próprio direito, existentes nas próprias cartas magnas, presentes nas próprias constituições, dando ao soberano poder extraordinário garantindo que as açõeslimite tomadas naquelas condições sejam contempladas com algum nível de anistia e conciliação jurídica. Nesse sentido, Benjamin se torna a principal referência de Agamben para sustentar a exploração desse espaço entre o direito e a vida, a dialética entre exceção e a liberdade. Agamben diz na página 49 de seu estado de exceção:

É como se o direito contivesse uma fratura essencial entre o estabelecimento da Norma e sua aplicação e que, em caso extremo, se pudesse ser preenchido pelo Estado de exceção, ou seja, criando-se uma área onde essa aplicação é suspensa mas a lei enquanto tal permanece em vigor (AGAMBEN, 2004, p. 49)

Para este texto, aqui está o principal liame entre Benjamin e Agamben e é nesse espaço que exploraremos a ideia de absorção dos conceitos de violência no debate sobre o estado de exceção pelo campo das Relações Internacionais, com o sentido de tentar entender a emergência de governos de natureza autoritária em várias partes do mundo. Mas não somente isso. Trata-se também da incorporação pelos Estados, entendidos como soberanos, de práticas dessa natureza. A reserva aonde Agamben vai se abastecer para explorar o estado de exceção está 
inicialmente no texto "Sobre a crítica do poder como violência" de Walter Benjamin. Há um capítulo inteiro no "Estado de Exceção" que trata de forma muito completa a remissão que o autor italiano faz aos estudos benjaminianos.

O capítulo se intitula "Sobre o vazio" e aponta as relações de Benjamin com outro autor alemão contemporâneo seu, Carl Schmitt, e levanta a hipótese de que toda a teoria política schmittiana é produzida em resposta a este ensaio sobre a violência escrito por Benjamin, o ensaio citado acima. Benjamin desenvolve o conceito de violência pura como sendo aquele que consegue romper a relação entre a violência fundacional -- que aquela que cria o direito -- e a violência que mantém esse direito em vigor e funcionamento. O esforço de Schmitt (2006) é precisamente o de tentar trazer esse conceito de violência pura, rebelde e radical por natureza, para o interior da ordem jurídica garantindo a redefinição radical da função do soberano.

É nesse debate da interação entre a violência e o direito que se percebe como a violência é estatutária da ação humana e consequentemente fundamento de sua existência e dos agrupamentos sociais que se formam a partir disso chegando até o nível, diz Agamben, dos Estados e do sistema que se forma da interação entre eles. É nessa percepção que Agamben percebe a transmutação da lei em vida completando o ciclo outrora imperfeito entre o espaço separado que existe entre os dois mas que se completa e que se sobrepõe de forma agora perfeitamente encaixável.

Feita essa breve apresentação sobre Agamben, pensamos que é hora de reportar a Benjamin para extrair dali aquilo que de fato tange ao sistema de Estados. Adianto que o elemento chave é aquilo que rege as Relações Internacionais em sua condição mais básica: a guerra. No ensaio "Sobre a crítica do poder como violência" é preciso inicialmente admitir que Benjamin atua no campo semântico onde o termo poder e o termo violência se tocam. Nesse sentido, aponta tradutor da última edição de "O anjo da história" de Walter Benjamin, que o termo poder está sempre de certa forma implicado com a violência, também enraizada a dimensão da violência do poder, constitutiva do Estado (BENJAMIN, 2016). Benjamin fala sobre as concepções de violência a partir da modernidade, sobretudo aquela que se assumiu como dominante na teoria do direito desde a revolução francesa. 
A violência seria um produto da natureza e desde que condicionada a fins justos, como uma ferramenta fundamental disponível aos viventes. Esta percepção se associada de forma deliberada ou não à perspectiva filosófica de Bento de Espinosa e a teoria da seleção natural como disposta um pouco mais na frente por Charles Darwin, sendo estes bons dois exemplos citados para definir esse paradigma da violência incorporado ao direito -- àquilo que Benjamin chama de o direito natural. No lado oposto está o chamado direito positivo que tenta fundamentar o poder como parte de uma evolução histórica, à moda do que o positivismo das Relações Internacionais costuma afirmar. Aqui se busca garantir exatamente o que é justo ou injusto sobre a perspectiva daquele que adquire o poder dessa evolução histórica (BENJAMIN, 2016).

O sistema internacional tem o seu surgimento pelo menos no mundo ocidental o período anterior à Revolução Francesa, na chamada Paz de Vestfália de 1648. A correlação que se pode fazer aqui e que argumentam é que os Estados, a partir de um determinado momento, passaram a deliberar sobre os fins justos de uma guerra e a guerra em si passa a ser é um elemento cada vez mais a ser rechaçado na relação entre pares soberanos. Portanto, qualquer tipo de violência que não parta dos Estados é por conta disso considerada injusta e só os Estados operando por conceitos como a razão de estado e os seus interesses legítimos podem vir a exercer a violência no cenário internacional dentro dos limites da justiça e da legalidade. Qualquer outro tipo de violência não é possível e daí, por exemplo, surge todo debate das Relações Internacionais sobre o direito de resistência e de autodeterminação dos povos. O que pretendemos argumentar aqui é que os estados para garantir a sua soberania e a sua condição dentro de uma hierarquia internacional podem eventualmente expandir a excepcionalidade do Estado de exceção para o nível permanente de ação dado as condições de ameaça e de necessidade que eventualmente o estado em si vem a definir como tal. (GONÇALVES; SILVA, 2010, p. 48)

O que está aí colocado são os critérios de diferenciação entre aquilo que pode ser dito legítimo ou ilegítimo sobre o poder e sobre seu exercício. E no geral a construção da ordem jurídica a partir da tendência dominante entre o direito positivo e o direito natural é a definição de que existe a possibilidade da utilização individual da violência, mas que somente o direito pode vir a definir se esta utilização é justa 
ou injusta. Dessa forma, deve-se cercar essa utilização com os elementos que constituem a ordem jurídica e o direito, dentro do limite do que pode ser compreendido como violência justa. Deve-se cercar pelos elementos que constituem a ordem jurídica e o direito o quê dentro do limite da violência pode ser compreendido como violência. E daí pode-se deduzir, acompanhando o que pensa Benjamin, que o direito e a ordem jurídica entendem a ação individual e a utilização individual da violência, mesmo em casos de autoproteção, como a possibilidade de subversão perigosa do próprio direito. É, portanto do interesse do direito monopolizar o poder e como dito acima, a violência (BENJAMIN, 2016). Benjamin explora essa acepção da existência de um dito direito de fazer a guerra. A guerra está relacionada à definição de formas possíveis de violência e que os objetivos são os seus fins naturais, os seus interesses enquanto Estado soberano, e em momentos de grave condição e deterioramento das relações, podem eventualmente cometer violência de um contra os outros. A guerra assume a partir dessa linha de pensamento o caráter constitutivo da própria ordem legal internacional.

* Se faz necessário aqui abrir-se o primeiro apêndice deste texto. Se há um tema Central para o estudo das relações internacionais, esse é o tema da Guerra. As Relações Internacionais enquanto disciplina e área de conhecimento definida como tal tem exatamente como marco temporal as duas guerras mundiais. Seu objetivo primordial era produzir conhecimento para que os eventos da guerra fossem mitigados e que a paz fosse o traço final das relações entre os Estados, ou pelo menos que o sistema estivesse em melhor condição do que no tempo entre os anos de 1914 e 1945, quando efetivamente se tentaram construir organismos internacionais. A guerra pode ser definida "como a condução de atos sistemáticos de violência material ou psicológica executados de forma mais ou menos organizados por grupos sociais que se contrapõem motivada por ou em busca de interesses considerados essenciais e que não foram obtidos por meios pacíficos de solução de controvérsia." (GONÇALVES; SILVA, 2010).

Bonanate (2001) especifica talvez aquele que é predominantemente o principal dos modelos de guerra chamado por ele aqui e por muitos outros de modelo clausewitziano. Ainda hoje, nas relações internacionais, o estrategista 
alemão Carl Von Clausewitz é bastante reverenciado e sua definição sobre a guerra é relativamente simples e profundamente poderosa: "a guerra é, portanto um ato de violência com qual se pretende obrigar o nosso oponente a obedecer à nossa vontade" (CLAUSEWITZ, 2017, p. 30).

No cruzamento de informação com Benjamin e com Agamben nesta percepção inegavelmente diferente sobre a guerra, argumenta-se que a vontade primordial é aquela que garante ao soberano o direito de ter vontade de poder, e que a submissão do adversário se transforma em exercício da legalidade, e qualquer contra-ação que conteste isso é considerada ilegal --- e, portanto injusta --- tanto no plano das relações humanas quanto no plano das relações entre os Estados (BENJAMIN, 2016). Nesse sentido a guerra acaba por demonstrar uma natureza majoritariamente social, menos um fenômeno coletivo e mais uma tecnologia de poder como muitas outras, adaptáveis ao interesse de quem têm controle sobre as instituições e consegue articular aos seus interesses.

Os diferentes paradigmas de Relações Internacionais tanto aqueles dentro da percepção positivista e tradicional sobre o poder quanto aqueles que se encontram à margem do pensamento tradicional divergem muito quanto ao espírito e a natureza da Guerra. Enquanto se adere às perspectivas positivistas, a guerra é elemento inerente do sistema internacional parte inextricável da existência dos estados nacionais e da defesa dos seus interesses. O sistema é anárquico e a colaboração não é compreensível se não for dentro da lógica da maximização do Poder dos estados nacionais. Bobbio (1998) apresenta uma importante contribuição aceita nas Relações Internacionais sobre o status da Guerra a partir da evolução do conceito de guerra justa e que por conta disso se toca no debate apresentado aqui por Benjamin e, subsequentemente, Agamben.

Durante toda a Idade Média, a guerra era um meio aceito para se atingir a justiça desde que a guerra fosse autorizada por um poder considerado legítimo, que a justificativa fosse uma justa causa, a intenção para existência da Guerra fosse uma intenção justa e que para que essa a realização causa justa nenhum outro meio fosse possível de ser utilizado, sendo a guerra sua última ratio. (BOBBIO et al., 1998). O sistema westfaliano criou novos códigos para condução lícita da guerra, inclusive criando arranjos mais eficientes para que a guerra fosse mitigada e que o balanço entre as potências fosse o elemento-chave da manutenção de um equilíbrio 
dentro do sistema. De qualquer forma independente do momento histórico aqui apresentado, desde a Idade Média até os dias de hoje, parece ainda garantido ao Estado e, portanto soberano no que se refere ao campo das Relações Internacionais a última palavra quando se refere a existência de uma guerra justa. São os estados que definem a licitude de uma guerra e a razão de Estado ainda permanece como parâmetro básico para definição desses interesses (MORGENTHAU, 2003).

Voltemos ao debate inicial. A manifestação do exercício da violência monopolizada e da sua relação com a guerra é chamada de militarismo por Walter Benjamin e definida "como a compulsão algum uso generalizado da violência para atingir os fins do Estado" (BENJAMIN, 2016, p. 66). O objetivo da violência que é transmutado e está na utilização da violência como elemento e forma de garantir os objetivos do direito. Benjamin chama atenção à lei do serviço militar obrigatório algo que mudou diametralmente a face do conflito deflagrado na Europa após a Revolução Francesa e que foi utilizado em larga escala por Napoleão Bonaparte. A conscrição obrigatória é uma forma de submissão à lei. Uma forma evidente de monopólio do uso das armas do poder e da violência, subordinada duramente a uma doutrina que inicialmente pode parecer exclusiva da formação das Forças Armadas, mas que invariavelmente se relaciona com os interesses do Estado desde que esta seja submetida ao poder civil.

Aqui se pode afirmar e identificar o surgimento do poder como violência e a maneira pela qual interfere de maneira contundente na ordem jurídica estabelecida em sua manifestação que costuma ser exercida pelos braços armados do Estado. É o poder soberano atuando sobre a vida e a morte para além do próprio direito e para além de qualquer outra aplicação da lei, o ato do direito em que se passa a se ocupar da morte, do thanatos, aquilo que se costuma chamar "tanatopolítica" (AGAMBEN, 2004). Nisto a polícia passa a ser o elemento primordial, o veículo da ação do estado. A força da lei e do seu exercício monopolista da violência acaba por efetivamente se atingir sobre grupos mais vulneráveis que não consegue eventualmente se defender da lei o pela qual a lei é construída contra ela nunca ao seu favor sempre em seu detrimento (BENJAMIN, 2016). A polícia, portanto, é a manifestação do militarismo é poder que institui o direito e que mantém o direito já que está colocado à sua disposição para garantir naquele fim de forma objetiva e cega. Se o poder não tem forma, sua intervenção é permanente, como se afirmam 
ser as razões de insegurança ou ameaça. A polícia é a presença do poder que é onipresente e invisível, e sua existência, diz Benjamin, é a materialização mais crua do Estado, do poder e da violência, logo mais distante dos limites estabelecidos pelo poder constituído e, portanto mais degenerada, quanto aos limites que uma democracia consegue estabelecer. (BENJAMIN, 2016).

Nesse momento já podemos estabelecer novas partes desse diálogo entre o pensamento de Walter Benjamin e o pensamento de Giorgio Agamben acerca do Estado de exceção e de como este pode se desdobrar de forma conceitual e prática no trato das questões internacionais. É preciso para isso inaugurar outras partes dessa discussão. Uma destas partes é aquela que trata do conceito de necessidade que, articulada ao conceito de ameaça, pode ser a chave da pesquisa que estamos em empreender aqui. Tanto o conceito de necessidade quanto o conceito de ameaça são elementos relativos, reativos, muitas vezes subjetivados pelos interesses do soberano e no caso do sistema internacional pelo interesse do Estado. Dessa forma não há desambiguação, diferenciação entre necessidade e ameaça. Ao contrário, há convergência e muitas vezes essa convergência é utilizada na construção de discursos para justificar algum tipo de ação internacional ou algum tipo de violência.

Agamben admite que o estado de exceção é uma prática corriqueira entre os Estados contemporâneos, dos mais democráticos aos mais autoritários (AGAMBEN, 2004). Isso significa dizer que também comumente o conceito de necessidade e o conceito de ameaça são articulados em discursos deliberadamente voltados para manutenção de sistema internacional da forma como as relações de poder estão organizadas. Sendo assim o extra-jurídico se transforma em Direito, e a diferenciação inicial entre o fato e a norma deixa de ser vista dissociadamente. Basta que em algum momento impere a necessidade de que a hierarquia internacional seja mantida, ou que a partir da visão do soberano, algum foco de insegurança surja.

* É preciso abrir novo parêntese aqui para debater a natureza do sistema internacional e do que se admite como segurança. Wendt é talvez o teórico que dentro dessas visões mais realistas das relações internacionais consegue empurrar o conceito de anarquia internacional e de segurança ao seu limite, e dessa forma, 
apresenta argumento é capaz de desmontar a percepção tradicional sobre a natureza do sistema internacional e o que se define como ameaça e segurança aceito de forma geral pelas teorias tradicionais de Relações Internacionais (WENDT, 2014).

A diferenciação entre racionalistas (ARON, 2002; MORGENTHAU, 2003; KEOHANE, 1992) e reflexivistas (ADLER, 1999; COX, 2007 ;WENDT, 2014) no campo das Relações Internacionais conta dessa diferenciação que precisa ser feita entre os pensamentos mais positivistas e aqueles que são intitulados póspositivistas. Não cabe aqui entrar tão profundamente nessa diferenciação o grosso modo o que se fala aqui sobre o sistema internacional é que ao contrário de ter produzido uma anarquia Geral de todos os estados podem competir e o estado de guerra é permanente há uma relação diferente estabelecida em muitos níveis em diferentes níveis e que exerce liderança a partir desses níveis criando um complexo sistema de hierarquia internacional (LAKE, 2009).

Nesse sentido, a Hierarquia transforma as relações entre os Estados porque de fato a manutenção de posições importantes nessa complexa rede de relações de poder passa por elementos mantidos dentro da legalidade e muitas vezes fora da legalidade ${ }^{2}$. Esse sistema é ainda mais complexo. Em seu fundamento básico ele é composto somente por estados ou seja as unidades básicas do sistema internacional. Entretanto a história global mostra que a presença de atores não nacionais e transnacionais existe desde da idade média. A própria abordagem estadocêntrica é problemática e isso fica mais Evidente com o fim da guerra fria. Participam agora dessa rede complexa, os grandes conglomerados internacionais grupos de libertação, organizações não governamentais que agem permanentemente como atores desse processo, organizações internacionais como as próprias Nações Unidas, grupos criminosos transnacionais, think tanks, entre outros (WILLETS, 2006).

A construção esse complexo sistema internacional prescreve também necessariamente a definição de uma norma internacional. Nesse ponto, a diferença entre a norma que se exerce dentro dos estados e do sistema de estados é bastante

\footnotetext{
${ }^{2}$ Este debate valeria uma outra pesquisa, quase como um estudo de caso, dentre muitos casos que o planeta apresenta hoje, mas de fato, não há tempo e nem espaço para isso aqui. Sobre a Lei Patriótica nos Estados Unidos, ver ETZIONI (2015).
} 
relevante. Os espaços vazios em que o direito internacional ainda não tem legitimidade para ocupar são muito grandes. No entanto, a utilização de mecanismos excepcionais para manutenção da hegemonia de certos Estados em relação a outros ou em relação a todo o sistema e a transformação desses expediente em algo permanente é um processo não do pós-guerra fria mas depois 11 de setembro. Quer dizer, no que a norma não alcança, os Estados agem de forma indiscriminada, e também indiscriminadamente empurram os limites do legal para práticas antes não previstas pelo ordenamento jurídico internacional (ETZIONI, 2015).

Dessa forma argumentamos que o exercício de poder hegemônico é sustentado e mantido por ações excepcionais transformadas em permanente no sistema internacional --- é simbólico o caso da lei patriótica dos Estados Unidos no pós 11 de setembro (AGAMBEN, 2004). Isto porque todos os elementos de violência de países em posição intermediária ou inferior na hierarquia internacional são enquadrados imediatamente dentro de uma norma internacional que vige e que thes é aplicada. A violência pura e o direito de resistência, como apontava Benjamin (2016) e como depois simbolizou muito claramente Schmitt (2006), enquadrada pelo direito internacional e portanto colocada como ilegal, moralmente injusta e passível de sanções internacionais. Os países em condição acima dessa hierarquia condição superior nessa hierarquia o mecanismo funciona ao contrário: objetivo de manter a sua legalidade e, em nome de questões subjetivas, percepções de aliança e de necessidade, se utilizam de mecanismos exteriores à norma, outrora excepcionais, mas agora permanentes. Se a ameaça é permanente a necessidade também é permanente e portanto os expedientes extralegais também são.

\section{DESDOBRAMENTOS FINAIS}

Podemos então concluir esta digressão com algo mais profundo do que foi apresentado acima. Dentro das Relações Internacionais, o problema da guerra nunca é dissolvido de vez, sempre está a espreita, mas o discurso estabelecido, de que o sistema internacional é anárquico, conflitivo e povoado somente por estados nacionais, passa a compartilhar espaço com vozes discordantes, interessadas na investigação sobre a origem destes discursos dominantes e na compreensão de outras formas de vida internacional. 
É importante ressaltar que para estes teóricos de Relações Internacionais posicionados fora das linhas estabelecidas pelo positivismo tradicional, as idéias importam e o discurso é uma importante força que define, entre outras coisas, como os Estados se comportam. Para pensadores como Ashley (1994), a desconsideração do discurso e a tentativa de legitimação científica isenta de subjetividade que se tenta colar no realismo tradicional das Relações Internacionais é um problema de segurança, um foco de insegurança. A imagem que se constrói sobre as relações entre os Estados estimula o conflito, maximiza a ameaça e interpreta o mundo a partir das relações que se constroem nos países que controlam essa hierarquia, que dominam mais do que são dominados. Isso significa dizer que mesmo que a noção de ameaça e de violência não seja a mesma do fim da Guerra Fria, outros elementos foram incorporados no elenco de fatores de desestabilização, isto é, aquilo que pode ameaçar os Estados soberanos em sua condição de segurança (GEORGE, 1994).

A guerra então teria mudado sua característica principal (KALDOR, 2013). Estado não é o ator único do sistema internacional, e isto teria causado um deslocamento importante, das ameaças somente originárias de outro Estado para o campo das múltiplas ameaças partidas dos múltiplos atores. Muitos temas foram securitizados (BUZAN e HANSEN, 2012), inclusive a pobreza e a desigualdade entre os indivíduos, seus movimentos sociais e suas maneiras de agir no internacional. Há uma disputa em aberto sobre a globalização teria trazido mais ou menos segurança para o sistema internacional e é muito possível dizer que a história continua seu rumo, dessa vez adicionada a estes fatores de desestabilização que vem de todos os pontos possíveis --- falava-se em fim da História (FUKUYAMA, 1992), mas isso hoje parece cada vez mais a utopia realista (GIDDENS, 1998).

A era da guerra total está na sua fase citadina, campo este essencial do biopoder e da exceção. Se a guerra antes era distorção da ordem, instabilidade, ela hoje é sombra que atemoriza a vida em sociedade. Na cidade as tensões estão colocadas, concentradamente. Os ativos militares, políticos e econômicos estão aglutinados (AMAR; BRANCOLI; RODRIGUES, 2017). Essa nova racionalidade do poder, e portanto da violência e da guerra, se organizou diferente da guerra entre Estados. Os "estados de violência" (GROS, 2009) incorporam estes atores nãoestatais e estas ameaças de múltiplas fontes, todos atuando nas complexas redes 
urbanas. O militarismo citado lá atrás por Benjamin é hoje militarismo urbano (GRAHAM, 2010), e a experiência de controle e vigilância, do cidadão pelo soberano, é permanente. Dado que a ameaça é transnacional e as fronteiras entre os Estados são cada vez mais esfumaçadas, a relação inclusive passa a ser outra, monitorando-se um cidadão em um outro Estado, de outra nação, numa onda maciça de informação a ser interpretada.

A polícia se militariza e é empregada em cenário não-nacional. Coerentemente, as políticas de segurança são militarizadas (NEOCLEOUS, 2014) e as Forças Armadas são comumente utilizadas na cidade, e ambos os processos são um permanente reforço à difusão do medo da ameaça e da insegurança, à criação de inimigos permanentes, recriando localmente as dialéticas do dentro/fora do Estado, do nacional/internacional, internalizando junto à ameaça que antes era fator exclusivamente externo (GRAHAM, 2010).

O espaço é instrumentalizado politicamente (LEFEBVRE, 2003), biopolitizado, imunizado (ESPOSITO, 2017), domínio prático da ação zoopolítica. O forte traço individualista, neoliberal, forja uma "nova governabilidade da insegurança social" (WACQUANT, 2009). O aparato de poder centraliza a administração social, sobretudo no que se refere àquilo que ameaça -- pobres, negros, imigrantes, subversivos, a ameaça bacteriológica -- e o Estado age sobre a vida do indivíduo, afim de modelar seu comportamento dentro de uma ordem moral e econômica específica. Os controles civis sobre o Estado se dissipam, as democracias se fragilizam, as resistências são esvaziadas. Os movimentos sociais são criminalizados, enquadrados no aparato repressivo.

Agamben passa a ser, portanto, um importante instrumento na compreensão deste mundo que emerge a toda hora de forma diferente do que era antes. A biopolítica é, sem dúvida, método e conceito já consolidado nos estudos sobre os fenômenos internacionais, mas é preciso reacender debates sobre os temas de violência e da exceção porque estes são elementos constitutivos do real. Assim, tentamos argumentar com este texto que há uma grande avenida de possibilidades para que o longo trabalho de Giorgio Agamben rompa a barreira da teoria política e da filosofia do direito e passe para o campo das ciências sociais aplicadas, por assim dizer, onde estão a Ciência Política e as Relações Internacionais, por exemplo. É desta maneira, com novos filtros, que poderemos ver os desafios que se 
avizinham, propor soluções novas baseadas naquilo que já temos de conhecimento acumulado e que, por conta de fronteiras artificiais que criamos entre as ciências, impedimos que este circule como deveria.

\section{REFERÊNCIAS}

ADLER, Emanuel. O construtivismo no estudo das relações internacionais. Lua Nova, v. 47, p. 201-246, 1999.

ARON, Raymond. Paz e guerra entre as nações. UNB/IPRI, 2002.

ASHLEY, Richard K. The poverty of neorealism. International organization, v. 38, n. 2, p. 225-286, 1984.

BENJAMIN, Walter. O Anjo da História. Autêntica: São Paulo, 2016.

BOBBIO, Norberto et al. MATTEUCCI, Nicola; PASQUINO, Gianfranco. Dicionário de política, v. 1, p. 382, 1998.

BONANATE, Luigi. A Guerra. São Paulo: Estação Liberdade, 2001.

BUZAN, Barry; HANSEN, Lene. A evolução dos estudos de segurança internacional. Tradução Flávio Lira. São Paulo: Ed. da UNESP, 2012.

COX, Robert W. Gramsci, hegemonia e relações internacionais: um ensaio sobre o método. Gramsci, materialismo histórico e relações internacionais. Rio de Janeiro: UFRJ, p. 101-23, 2007.

ESPOSITO, Roberto. Bíos: Biopolítica e Filosofia. Belo Horizonte: Ed. UFMG, 2017.

ETZIONI, Amitai. How patriotic is the Patriot Act?: freedom versus security in the age of terrorism. Londres: Routledge, 2005.

FOUCAULT, Michel, et al. Segurança, território, população: curso dado no collège de France (1977-1978). Rio de Janeiro: Martins Fontes, 2008.

FUKUYAMA, Francis. O fim da história e o último homem. Rio de Janeiro: Rocco, 1992.

GEORGE, Jim. Discourses of global politics: a critical (re) introduction to international relations. Boulder, CO: Lynne Rienner Publishers, 1994.

GIDDENS, Anthony. The Third Way. The renewal of social democracy. Cambridge: Polity Press, 1998. 
GONÇALVES, Williams; SILVA, Guilherme. Dicionário de relações internacionais. Barueri: Manole, 2010.

GROS, Frédéric. Estados de violência: ensaio sobre o fim da guerra. Tradução de José Augusto da Silva. Aparecida: Ideias \& Letras, 2009.

KALDOR, Mary. New and old wars: Organised violence in a global era. Nova Jersey: John Wiley \& Sons, 2013.

KEOHANE, Robert O. Soberania estatal e instituições multilaterais: respostas à interdependência assimétrica. O futuro do Brasil: a América Latina e o fim da guerra fria. São Paulo: Paz e Terra, 1992. p. 165-191.

LAKE, David A. Hierarchy in international relations. Nova lorque: Cornell University Press, 2009.

LEFEBVRE, Henri. The urban revolution. Minneapolis: University of Minnesota Press, 2003.

MONTAIGNE, Michel de. Ensaios. Tradução de Sérgio Milliet. São Paulo: Nova Cultural, 1996. v. 1.

MORGENTHAU, Hans J. A política entre as nações: a luta pela guerra e pela paz. Brasília: Editora Universidade de Brasília/Instituto de Pesquisa de Relações Internacionais, 2003.

NEOCLEOUS, Mark. War power, police power. Edinburgh: Edinburgh University Press, 2014.

RODRIGUES, Thiago; BRANCOLI, Fernando; AMAR, Paul. Global Cities, Global (in) Securities: An Introduction. Contexto Internacional, v. 39, n. 3, p. 467-476, 2017.

SCHMITT, Carl. Teología política. Editora del Rey, 2006.

VON CLAUSEWITZ, Carl. Da guerra. Rio de Janeiro: Martins Fontes, 2017.

WACQUANT, Loïc. Punishing the poor: The neoliberal government of social insecurity. Duke University Press, 2009.

WENDT, Alexander. Teoria social da política internacional. Rio de Janeiro: PUCRio, 2014.

WILLETTS, Peter. Transnational actors and international organizations in global politics. In: BAYLIS, John; SMITH, Steve The globalization of world politics. Oxford University Press, 2006. v. 2.

Artigo recebido em: 28/09/2017

Artigo aprovado em: 11/12/2017

Artigo publicado em: 18/12/2017. 